\section{Trying to be wise before the event}

\author{
Alastair Hay
}

In Search of Safety: Chemicals and Cancer Risk. By John D. Graham, Laura C. Green and Marc J. Roberts. Harvard University Press:1988. Pp.336. \$35, $£ 27.95$.

Living in a Chemical World: Occupational and Environmental Significance of Industrial Carcinogens. Edited by Cesare Maltoni and Irving $\mathrm{J}$. Selikoff. The New York Academy of Sciences: 1988. Pp.1,045. Soft cover $\$ 260, £ 140.50$.

SEARCHING for safety is rather like the quest for the Holy Grail. Like the Grail, absolute safety probably does not exist, but that doesn't matter when there is so much to be discovered in striving for it. And safety is intangible - it can be measured only by negatives, that is, the absence of illness, injury or dead bodies.

Sadly, we cannot talk about negatives when considering the safety record of many countries over the past few years. Take British industry and agriculture. The huge loss of life in the Piper Alpha disaster in the North Sea dwarfs every other incident recorded in annual statistics, which show that deaths from accidents on building sites and farms are on the increase, whereas they have fallen in the manufacturing and mining industries. But economic recession has forced the latter industries to contract, and reduce their workforces, and so the apparent improvement in their safety record is not real.

Accident statistics are tangible enough. More difficult to compute are the deaths caused by exposure to hazardous substances, particularly carcinogens, at work. Many of these cases never get into the records. Given the choice we would all avoid contact with compounds that might cause cancer, but for millions of workers there is no choice - exposure to these agents is a fact of life and the decisions governing them are made by someone else. In Search of Safety describes how some of these decisions are made in the United States, and I found the book exemplary in its discussion of the often conflicting evidence about hazards, the activities of various pressure groups and the horse-trading that is so much a part of the regulatory process.

To illustrate their theme, Graham and his co-authors chose two controversial chemicals - formaldehyde and benzene - to which we are all exposed, be it at work or through urea-formaldehyde insulation in our homes, through car exhausts and through petrol at filling stations. Rules governing both chemicals have been laid down by several regulatory regulatory decisions in the courts.

Benzene raises other problems. Epidemiological studies in Turkey and Italy have established beyond doubt that benzene causes leukaemia in human beings, but the critical aerial concentration of the chemical is still not known. And there is some irony in the fact that regulatory agencies have been more concerned to reduce the average exposure to benzene over the working day, whereas In Search of Safety points out there is now good evidence to suggest that exposure to high concentrations over short periods is far more dangerous. In view of this, Graham and his co-authors suggest that "occupational exposure standards that significantly reduce allowable peak exposures might be more productive than those that strive merely to lower the TWA [time-weighted average]".

To round out the book, the authors consider the role of the courts in evaluating evidence, whether yet more scientific investigations would help, or hinder, regulatory action, and what role scientists ought to play in the process. Given the complexity of the arguments involved in regulation, they believe that the threat of litigation by industry has forced regulatory agencies to be more conservative in their rulings than the agencies would have preferred. Disapproval of this state of affairs is evident in the book: "[judges] have no special claim to wisdom about how to act in the face of uncertainty or how to make value trade-offs between economics and health in the case of particular chemicals".

On the issue of scientific evidence, Graham and his colleagues conclude that more is not always helpful, and show how in some cases additional evidence has actually confused the picture. But they do believe that more knowledge about environmental groups, to challenge any

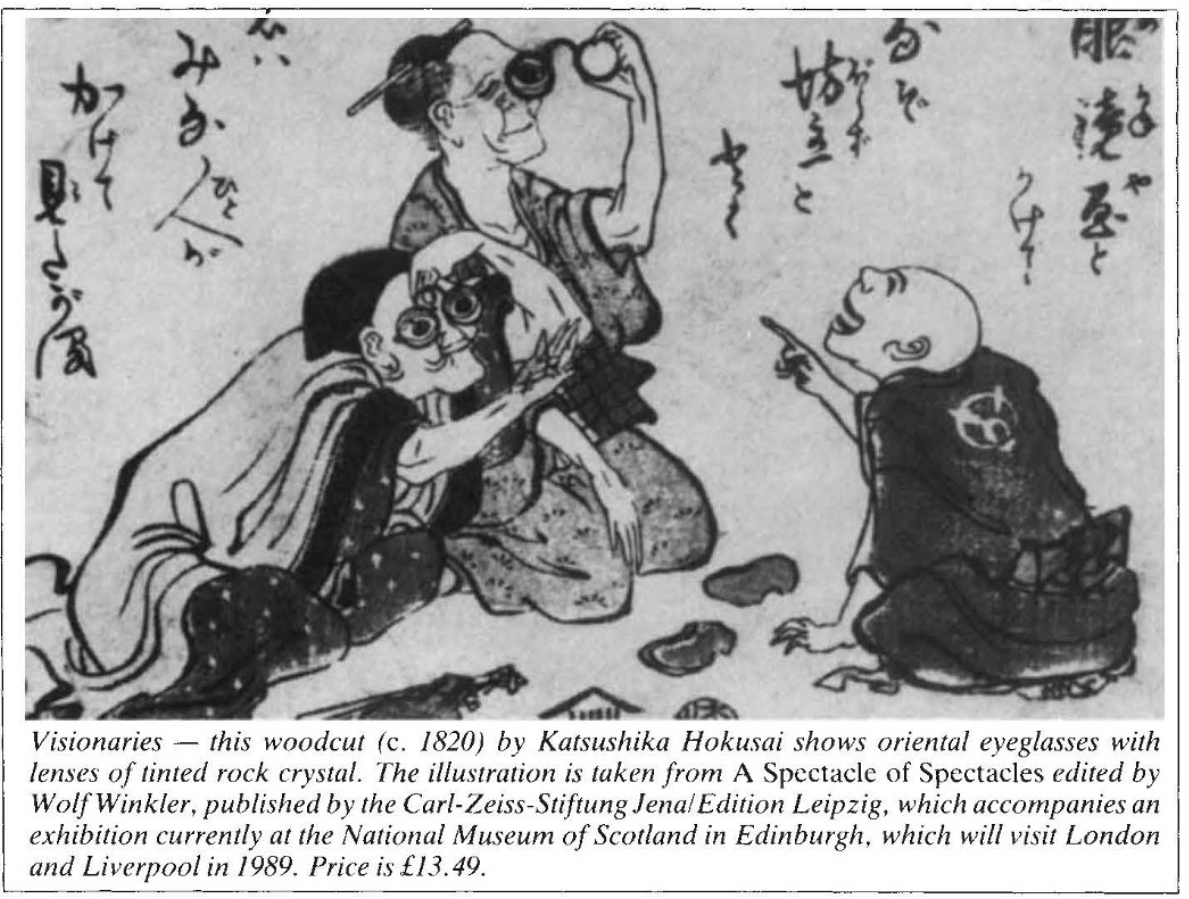

